\title{
Saccade latency indexes exogenous and endogenous object-based attention
}

\author{
Gözde Şentürk $^{1}$ • Adam S. Greenberg ${ }^{2}$ - Taosheng Liu ${ }^{1}$
}

Published online: 25 May 2016

(C) The Psychonomic Society, Inc. 2016

\begin{abstract}
Classic studies of object-based attention have utilized keypress responses as the main dependent measure. However, people typically make saccades to fixate important objects. Recent work has shown that attention may act differently when it is deployed covertly versus in advance of a saccade. We further investigated the link between saccades and attention by examining whether object-based effects can be observed for saccades. We adapted the classical doublerectangle cueing paradigm of Egly, Driver, and Rafal (1994), and measured both the first saccade latency and the keypress reaction time (RT) to a target that appeared at the end of one of the two rectangles. Our results showed that saccade latencies exhibited higher sensitivity than did RTs for detecting effects of attention. We also assessed the generality of the attention effects by testing three types of cues: hybrid (predictive and peripheral), exogenous (nonpredictive and peripheral), and endogenous (predictive and central). We found that both RTs and saccade latencies exhibited effects of both space-based and object-based attentional selection. However, saccade latencies showed a more robust attentional modulation than RTs. For the exogenous cues, we observed a spatial inhibition of return along with an object-based effect, implying that object-based attention is independent of space-based attention. Overall, our results revealed an oculomotor correlate of object-based attention, suggesting that, in addition to spatial priority, object-level priority also affects saccade planning.
\end{abstract}

Taosheng Liu

tsliu@msu.edu

1 Department of Psychology, Michigan State University, 316 Physics Rd, East Lansing, MI 48824, USA

2 Department of Psychology, University of Wisconsin, Milwaukee, WI, USA
Keywords Object-based attention · Eye movements · Visual attention

The amount of visual information available at any moment is far too sizable for our nervous system to handle. This requires some prioritization of information so as not to overwhelm the system. The enhancement of relevant stimuli and the suppression of irrelevant stimuli are, thus, crucial for survival. Attention serves to prioritize important stimuli by increasing the neural responses to attended ones and decreasing the neural responses to unattended ones (see Kanwisher \& Wojciulik, 2000 , for review). In certain circumstances, attention is able to select information on the basis of objectness (see Chen, 2012, for a review). Attending to an object enhances the properties of that object, such that (after reporting one object feature) it becomes easier to report a second feature of the attended object, versus reporting a feature of an unattended object (Duncan, 1984). The focus of the present study was to broaden our knowledge of the conditions under which attention is object-based.

In a seminal study, Egly, Driver, and Rafal (1994) investigated the effects of both space-based and object-based attention within a single paradigm. Two rectangles were shown on each trial. One end of a rectangle was cued, followed by a target at one of three locations: (1) the cued end of the rectangle (valid location), (2) the uncued end of the cued rectangle (same-object location), or (3) the equidistant end of the uncued rectangle (different-object location). Their results showed that less time was required to detect the target at the cued location than any other location - evidence of spatial cueing. Critically, target detection was also faster at the same-object than at the different-object location. This performance difference, often referred to as the "same-object advantage," cannot be explained by spatial attention, because the 
two invalid locations were equidistant from the cue. Hence, the same-object advantage reflects the attentional priority assigned to the cued object - that is, object-based attention. Further studies using the double-rectangle paradigm have shown that both detection (Atchley \& Kramer, 2001; He, Fan, Zhou, \& Chen, 2004; Lamy \& Egeth, 2002) and discrimination (Drummond \& Shomstein, 2010; Macquistan, 1997; Moore, Yantis, \& Vaughan, 1998; Shomstein \& Behrmann, 2008; Shomstein \& Yantis, 2004) performance exhibit a sameobject advantage.

Nearly all object-based attention studies have investigated covert attention - that is, attention in the absence of eye movements. In everyday life, however, people tend to fixate objects of interest via saccades (overt attention). Thus, in the interest of ecological validity, it is important to know whether objectbased selection occurs for overt attention - in other words, whether saccades are affected by the deployment of attention to the whole object once a part of the object has been selected.

The relationship between saccades and space-based covert attention has been of great interest to researchers. In particular, many studies have investigated how space-based attention affects the latency to initiate saccades, and have found that attention can have a small, but significant, effect on saccade latency. For example, Crawford and Müller (1992) presented exogenous cues followed by simple visual targets in a detection task and instructed participants to either execute an eye movement to the target or a keypress. They found that both saccade latency and keypress reaction time (RT) to targets at the cued location were faster than to other locations. These results suggest that exogenously driven space-based attention accelerates saccade preparation. Further studies have also shown that endogenous space-based attention, as manipulated by reward and target predictability, influences saccade latency. For example, differentially rewarding saccades to a specific location led to faster latencies to higher-rewarded locations than to other target locations (Kawagoe, Takikawa, \& Hikosaka, 1998; Rothkirch, Ostendorf, Sax, \& Sterzer, 2013; Takikawa, Kawagoe, Itoh, Nakahara, \& Hikosaka, 2002). Likewise, as the probability of target appearance increases at a location, the saccade latency to that location becomes faster (Abrams \& Jonides, 1988; Dorris \& Munoz, 1998; Murray \& Giggey, 2006). These studies established that saccade latency is a useful metric to index the deployment of attention.

The abovementioned studies on saccade latencies are consistent with the general notion that covert and overt attention share largely similar mechanisms, which is supported by findings showing coupling between saccades and attention (Deubel \& Schneider, 1996; Godijn \& Pratt, 2002; Hoffman \& Subramaniam, 1995; Kowler, Anderson, Dosher, \& Blaser, 1995; Shepherd, Findlay, \& Hockey, 1986). Indeed, the premotor theory of attention suggests that overt and covert attention are the same phenomena (see Rizzolatti, Riggio,
Dascola, \& Umiltà, 1987; Sheliga, Riggio, \& Rizzolatti, 1994). The similarity between covert and overt attention was further supported by physiological findings showing that saccade preparation and covert attention are processed in the same brain regions (for a review, see Awh, Armstrong, \& Moore, 2006). Although the coupling between covert and overt attention is generally accepted, some counterevidence has also challenged the strong coupling between covert and overt spatial attention. For example, attention is not always deployed to the saccade-prepared location (Hunt \& Kingstone, 2003; Klein, 1980), and attentional deployment does not necessarily engender saccade preparation (Juan, Shorter-Jacobi, \& Schall, 2004). In addition, saccade preparation deploys attention to the saccade-prepared location much faster than deployment of covert attention (Rolfs \& Carrasco, 2012). Lastly, physiological studies suggest that different subpopulations of neurons process attention and saccades (Juan et al., 2004; Sato \& Schall, 2003; Thompson, Bichot, \& Schall, 1997; Thompson, Biscoe, \& Sato, 2005). Thus, although covert and overt spatial attention are usually correlated, they do not have identical properties (see also Smith \& Schenk, 2012). Given the observed dissociations between overt and covert attention, one might not predict that saccades will follow the same pattern as covert attention in observing object-based effects as measured in the two-rectangle paradigm.

These considerations thus led us to investigate whether object-based attention also influences saccade latency. Few studies have investigated the effect of object-based attention on eye movements. McCarley, Kramer, and Peterson (2002) and Theeuwes, Mathôt, and Kingstone (2010) used the double-rectangle cueing paradigm to investigate how objectbased attention affects eye movements. In their experiments, after the initial spatial cue disappeared, participants first made a saccade to the cued location, which was followed by the presentation of three distractor letters and one target, each located at one end of one rectangle. The task was to report the identity/orientation of a small target letter that required foveating. Participants, thus, made a second saccade to the target, which became the focus of the analyses. Both studies revealed that the second saccade tended to stay within the cued object. Furthermore, McCarley et al., (2002) found that latency for the second saccade to the same-object location was faster than to the different-object location, although such a difference was not observed in the Theeuwes et al., (2010)'s study. A more recent experiment with a similar design using real-world pictures also reported that the second saccade latency to the same-object location was faster than the differentobject location (Malcolm \& Shomstein, 2015).

These results imply a relationship between object-based attention and eye movements, but they are inconclusive for several reasons. First, an effect of object-based attention on second saccade latencies was not consistently observed. 
Second, there was a potential low-level confound in the results for the second saccade, which in these studies always began at the cued location. However, once the eyes had landed on the cued location, there were also several retinal-level differences between the same-object and different-object locations. One of these was the presence of obstructing object edges in the path to the different-object location (which could impede saccades to this location), but an absence of such edges for the same-object location. More importantly, the saccade path to the same-object location was delineated by elongated lines (those of the rectangle edges) that were absent on the saccade path to the different-object location. "Following elongated edges" can produce the same effect as "obstructing object edges" - they both lead to faster RTs at the same-object location than the different-object location. Importantly, however, there is empirical evidence for the "following elongated edges" idea, such that the presence of contour lines on the saccade path biases eye movements along the direction of the contours (Wismeijer \& Gegenfurtner, 2012). Thus, the same-object advantage of eye movements in these studies might have been caused by the presence of guiding lines to the same-object location rather than by the effects of objectbased attention.

Notably, in these studies, the researchers did not focus on the first saccade, which is arguably a better measure of the initial distribution of attention to the entire display. Furthermore, at the time of the first saccade, the visual scene is symmetric, so low-level retinal features are equated (which serves to avoid the confound of guiding contours and obstructing edges detailed above). Our aim here was to investigate the effect of object-based attention on first saccade latencies in the double-rectangle paradigm. We also varied the nature of the initial cue, using exogenous, endogenous, and hybrid spatial cues, to examine the generality of the coupling between object-based attention and saccade preparation. In three experiments, we first measured the effect of objectbased attention via conventional keypress RTs, which provided a baseline measure. The saccade experiments used identical visual stimuli, but participants made a rapid eye movement to the target. We measured the latency of the first saccade to the target as an index of the initial distribution of attention. To preview our results, we found strong evidence that objectbased attention facilitated both keypress RTs and saccade latencies.

\section{Experiment 1: Hybrid cue}

The double-rectangle cueing paradigm first introduced by Egly et al. (1994) used a hybrid cue - that is, a peripheral cue that is also predictive of the target location. Previous research using the double-rectangle paradigm with hybrid cues has yielded results supporting Egly et al., (1994)'s original findings (Atchley \& Kramer, 2001; Moore et al., 1998; Shomstein \& Behrmann, 2008). Here, we also performed a replication of Egly et al.'s original finding under our experimental setup, which serves as a point of departure to explore object-based effects in a novel saccade task. In our first experiment with keypress responses (Exp. 1a), we predicted both space-based effects and object-based effects in keypress RTs. We then conducted an experiment to investigate whether the effect of object-based attention can be detected using saccade latency (Exp. 1b). If object-based attention affects eye movement preparation, we should find analogous effects in saccade latency: faster first saccade latencies for targets appearing at the invalid same-object location than for those at the invalid different-object location.

\section{Experiment 1a}

\section{Method}

Participants Sixteen participants (age $\sim 18-30$ years) provided written informed consent and took part in the experiment: all were students from Michigan State University. One participants' data were excluded due to excessive premature responses (61.25\% of trials). Participants had normal, or corrected-to-normal, vision and did not have any neurological or psychiatric disorders. They were compensated with course extra credit or $\$ 10 / \mathrm{h}$, with a bonus of $\$ 5$ after the completion of the experiment. The experimental protocol was approved by the Institutional Review Board at Michigan State University.

Apparatus and visual stimuli The experiment was programmed in MATLAB (The Mathworks, Natick, MA) with MGL extensions (gru.stanford.edu/doku.php/mgl/overview). The stimuli were displayed on a 19-in. CRT monitor (resolution: $1,024 \times 768$ pixels) at a vertical refresh rate of $100 \mathrm{~Hz}$. The viewing distance was $68 \mathrm{~cm}$ ensured via the use of a chinrest.

The background of the display remained black (luminance: $0.051 \mathrm{~cd} / \mathrm{m}^{2}$ ) throughout the experiment. The fixation cross (line length: $0.05^{\circ} \times 0.05^{\circ}$, line width: $0.03^{\circ} \times 0.03^{\circ}$ ) was a gray (luminance: $16.19 \mathrm{~cd} / \mathrm{m}^{2}$ ) "plus sign" located at the center of the screen. Following Egly et al. (1994), we used two rectangle outlines as objects. The inner areas of the rectangles matched the screen background and the rectangle edges were delineated by gray lines (thickness: $0.2^{\circ}$, luminance: $16.19 \mathrm{~cd} /$ $\mathrm{m}^{2}$ ). The distance from the centroid of the each rectangle to the fixation cross was $4.8^{\circ}$. In the vertical orientation, each object's centroid fell on the screen's horizontal meridian, whereas in the horizontal orientation, each object's centroid fell on the screen's vertical meridian.

The spatial cue was a white thickening (thickness $=0.4^{\circ}$, luminance $=64.78 \mathrm{~cd} / \mathrm{m}^{2}$ ) at one end of a rectangle. All three 
sides of the cue were equal to the length of the short edge of the rectangle. The target was a light gray circle $\left(\right.$ size $=1^{\circ} \times 1^{\circ}$, luminance $=35.71 \mathrm{~cd} / \mathrm{m}^{2}$ ) located at the end of the rectangle, at an eccentricity of $6.79^{\circ}$ (see Fig. 1 for example stimuli).

Design and procedure The experiments took place in a dimly lit room. A fixation cross and two objects appeared on the screen at the beginning of each trial. The orientation of the objects (vertical vs. horizontal) was randomized across trials. One second after the onset of the initial display, the cue appeared randomly at one of the four corners of the two objects for $100 \mathrm{~ms}$. After a 200-ms interval, the target appeared at the cued location on $60 \%$ of trials, at the uncued end of the cued object (same-object) on $10 \%$ of trials, and at the equidistant corner of the uncued object on $10 \%$ of trials (different-object). The remaining trials $(20 \%)$ were "catch" trials in which the target did not appear. There were ten blocks, each consisting of 80 trials.

Participants were instructed to keep their eyes on the fixation cross throughout the experiment and to quickly press the spacebar with their dominant hand as soon as the target appeared. In the absence of a correct keypress response (and on target-absent trials), the trial was terminated $2 \mathrm{~s}$ after the target had appeared. The subsequent trial began $500 \mathrm{~ms}$ after the termination of the previous trial (Fig. 1). Eye position was not recorded.

\section{Results}

For all statistical tests, we report the Greenhouse-Geissercorrected values when the correction is necessitated by Mauchly's test of sphericity.

Eligible trials We excluded all trials on which the RT was shorter than $200 \mathrm{~ms}$ or longer than 1,500 ms. The proportion of eligible trials in each condition was submitted to a 2 (Orientation: vertical, horizontal) $\times 3$ (Target Location: cued location, same-object location, different-object location) repeated measures analysis of variance (ANOVA). None of the effects reached significance (all $p \mathrm{~s}>.1$ ). On average, .96 of trials were eligible for the analysis.
Reaction time A 2 (Orientation: vertical, horizontal) $\times 3$ (Target Location: cued, same object, different object) repeated measures ANOVA was performed on the mean keypress RTs (Fig. 2). The main effect of target location was significant $\left[F(2,28)=8.38, M S E=3,651.12, p=.01, \eta_{\mathrm{p}}{ }^{2}=.37\right]$. Keypress RTs were faster for the cued location $(M=368.89$, $S E=18.83)$ than for both the same-object $(M=404.14, S E=$ 27.94, Cohen's $d=0.69)$ and the different-object $(M=413.77$, $S E=29.65$, Cohen's $d=0.8$ ) locations $(p s=.010$ and .008 , respectively). Importantly, RTs were significantly faster for the same-object than for the different-object location ( $p=$ .021 , Cohen's $d=0.67)$. The effect of orientation $[F(1,14)$ $\left.=0.51, M S E=148.69, p=.488, \eta_{\mathrm{p}}{ }^{2}=.04\right]$ and the interaction $\left[F(2,28)=0.94, M S E=285.12, p=.404, \eta_{\mathrm{p}}{ }^{2}=.06\right]$ were not significant.

As predicted, our results replicated Egly et al.'s (1994) findings using the double-rectangle cueing paradigm. First, target detection was fastest at the cued location, indicative of enhanced processing due to space-based attention. Furthermore, target detection was also faster at the sameobject location than at the different-object location. Given that these two locations were equidistant from the cued location, the observed performance difference cannot be attributed to space-based attention, but must be due to attention enhancing the representation of the cued object - an object-based attention effect (sometimes termed a "same-object advantage"). Given our successful replication of the manual RT results, we next used the double-rectangle cueing paradigm in an experiment with eye movement responses as the dependent measure.

\section{Experiment 1b}

\section{Method}

Participants Fifteen participants (age $\sim 18-30$ years) provided written informed consent and took part in the experiment: all were students from Michigan State University. One author (G.S.) participated in the experiment; none of the participants had taken part in Experiment 1a. The participant recruitment criteria were the same as in Experiment 1a.

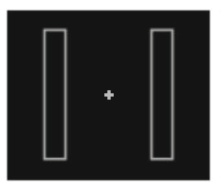

Preview: $1 \mathrm{sec}$

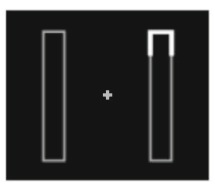

Cue: $100 \mathrm{~ms}$

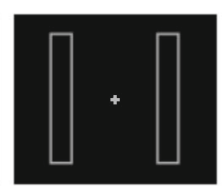

ISI: $200 \mathrm{~ms}$.

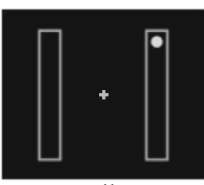

Target: until response/ $\max .2 \mathrm{sec}$.

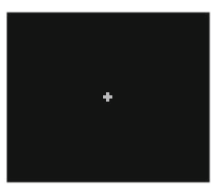

ITI: $500 \mathrm{~ms}$.
Fig. 1 Sequence of a trial in Experiment 1. The rectangles appeared in horizontal or vertical orientation (vertical is shown here). A peripheral cue flashed for $100 \mathrm{~ms}$. After a 200-ms interstimulus interval (ISI), the target appeared at the cued location (60\%), the invalid same-object location $(10 \%)$, the invalid different-object location $(10 \%)$, or it did not appear $(20 \%)$. ITI $=$ intertrial interval 


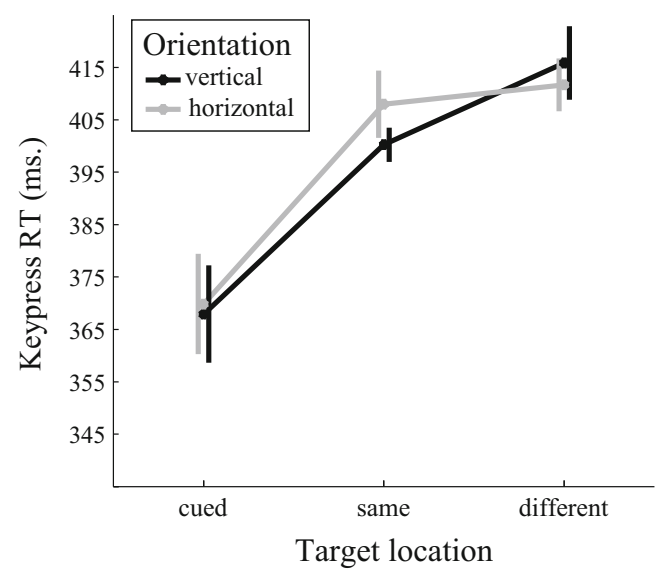

Fig. 2 Mean reaction times (RTs, in milliseconds) as a function of object orientation (vertical vs. horizontal) and target location (cued, same-object, different-object). Error bars show within-subjects standard errors, as suggested by Cousineau (2005)

Apparatus and visual stimuli Both the display and stimuli were identical to those in Experiment 1a. Eye movements were recorded by an EyeLink 1000 eyetracker (SR Research, Ontario, Canada) at a sampling rate of $1 \mathrm{kHz}$.

Design and procedure We included a training session in this experiment to familiarize participants with the use of saccades to indicate their responses. The training session and the experiment took place on the same day in a dimly lit room. Participants who had participated in a previous eye movement study in our lab were not required to complete the training session. The equipment and stimulus characteristics were identical in the training session and the experiment.

The experimenter was in the room during the training session. Before the beginning of the training session, a nine-grid calibration and validation was performed. A fixation cross appeared first for $800 \mathrm{~ms}$, followed by a target at one of four possible locations, corresponding to the corners of the rectangles in the main experiment (the rectangles were not displayed). The participants were instructed to keep their gaze at the fixation cross and make a quick eye movement to the target when it appeared. The target disappeared when the gaze stayed within a $2^{\circ}$ radius of the target for $200 \mathrm{~ms}$. In the absence of a correct eye movement, the target was removed from the screen after $2 \mathrm{~s}$. The next trial started after a 500-ms interval. The training session consisted of three blocks, with 40 trials per block.

The experimenter was also present in the room during the main experiment and during the calibration and validation of the eyetracker. The main experiment began after a successful calibration and validation procedure. The main experiment was run as explained in the Design and Procedure section of Experiment 1a, with the following exception: Participants moved their eyes to fixate the target instead of using keypresses to indicate target detection. They were instructed to (a) fixate the central cross until the target appeared, (b) make a quick eye movement to the target, (c) keep their gaze on the target until it disappeared, and (d) look back at the fixation cross afterward. The target disappeared if a participant's gaze stayed within $1.5^{\circ}$ of the target center for at least $200 \mathrm{~ms}$, which was defined as a correct response. In the absence of a correct eye movement (and on target-absent trials), the trial was terminated $2 \mathrm{~s}$ after the target appeared. The subsequent trial began $500 \mathrm{~ms}$ after the termination of the previous trial.

Data preprocessing We used SR Research's eye movement parser, set at the cognitive orientation, to detect saccades. The velocity threshold was $30^{\circ} / \mathrm{s}$, the acceleration threshold was $8000^{\circ} / \mathrm{s}^{2}$, and the motion threshold was $0.1^{\circ}$.

We performed offline drift correction of the eye movement data. The mean eye position during the initial $100 \mathrm{~ms}$ of a trial (i.e., the initial fixation period) was subtracted from the eye position values on that trial. The saccade latency was the time difference between the target onset and the saccade onset, and the saccade duration was the time difference between the saccade onset and saccade offset. We excluded the following types of trials from our analysis of the eye movement data: (1) eye movements that occurred within $75 \mathrm{~ms}$ of target onset (i.e., premature saccades), (2) failures to move the eyes on target-present trials within $500 \mathrm{~ms}$ of the target onset, (3) failures of the first saccade to reach the target (i.e., gaze landing $>2^{\circ}$ from target center), (4) saccade latencies outside the range of three standard deviations from that participant's mean, and (5) saccade durations outside the range of three standard deviations from that participant's mean.

\section{Results}

Eligible trials The proportion of eligible trials in each condition, after preprocessing, was submitted to a 2 (Orientation: vertical, horizontal) $\times 3$ (Target Location: cued, same-object, different-object) repeated measures ANOVA. The main effect of target location was significant, $F(2,28)=6.3, M S E=<$ $0.01, p=.006, \eta_{\mathrm{p}}{ }^{2}=.31$ : The proportion of eligible trials was higher when the target appeared at the cued location $(M=.87$, $S E=.03)$ than when the target appeared at the same-object location $(M=.82, S E=.03), p=.002$. We found no further significant differences between the target locations, all $p \mathrm{~s}>$ .05 . The effect of orientation and the interaction were not statistically significant (all $p \mathrm{~s}>.1$ ). On average, .84 of trials were eligible for the analysis. The proportion of trials that were eliminated due to mistakenly saccading toward the cued location did not depend on the configuration, the target location, or their interaction (grand $M=.11$, all $p \mathrm{~s}>.05$ ). Investigation of the proportion of trials eliminated due to making a wrong saccade followed by saccading to the target showed that no corrective saccades were made when the target 
appeared at the cued location. Among the invalidly cued locations, the proportion of corrective saccades depended on neither the orientation (horizontal vs. vertical), nor the target location (same-object vs. different-object location), nor the interaction between orientation and target location, all $p \mathrm{~s}>$ .5 (grand $M=.07, S E=.02$ ).

Saccade latency A 2 (Orientation: vertical, horizontal) $\times 3$ (Target Location: cued, same-object, different-object) repeated measures ANOVA was conducted on the mean saccade latencies (Fig. 3). The main effect of target location was significant $\left[F(2,28)=28.54, M S E=185.99, p<.001, \eta_{\mathrm{p}}{ }^{2}=.67\right]$. The mean saccade latency was faster to the cued location $(M=$ $208.68 \mathrm{~ms}, S E=5.68 \mathrm{~ms})$ than to the same-object $(M=$ $224.99 \mathrm{~ms}, S E=7.1 \mathrm{~ms}$, Cohen's $d=1.29)$ and differentobject ( $M=230.29 \mathrm{~ms}, S E=7.77 \mathrm{~ms}$, Cohen's $d=1.58)$ locations, all $p \mathrm{~s}<.001$. Importantly, the saccade latency to the same-object location was faster than that to the differentobject location ( $p=.012$, Cohen's $d=0.74)$. The effect of orientation $\left[F(1,14)=0.29, M S E=42.73, p=.596, \eta_{\mathrm{p}}{ }^{2}=\right.$ $.02]$ and the interaction $[F(2,28)<0.01, M S E=117.01, p=$ $\left..992, \eta_{\mathrm{p}}^{2}<.01\right]$ were not statistically significant.

Saccade gain and landing distance The endpoint accuracy of the saccades was measured to assess whether the observed differences in saccade latencies could be explained by a trade-off between saccade speed and landing precision. There are two measures of landing precision: The saccade gain ratio is calculated by dividing the measured distance of the saccade by the minimum distance to the target (Crawford \& Müller, 1992), and the landing distance is the distance between the saccade endpoint and the centroid of the target. Since saccade latencies were not influenced by orientation or the interaction between orientation and target location, we

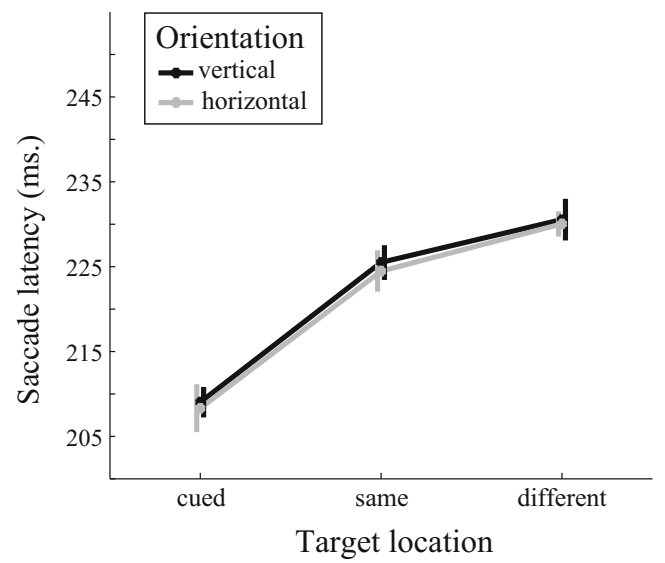

Fig. 3 Mean saccade latencies as a function of object orientation (vertical vs. horizontal) and target location (cued, same object, different object). Error bars show within-subjects standard errors, as suggested by Cousineau (2005) collapsed across orientations when calculating the saccade gain ratios and landing distances. From Experiment 1b onward, paired-sample $t$ tests are employed to compare the saccade gain ratios and landing distances between target locations.

The saccade gain ratio at the cued location $(M=1.01$, $S E=0.01)$ was larger than the saccade gain ratios at the same-object $(M=0.99, S E=0.01)$ and different-object $(M$ $=0.97, S E=0.01)$ locations. The saccade gain ratio at the same-object location was also higher than the ratio at the different-object location, all $p \mathrm{~s}<.005$. Landing distances did not differ between the target locations (grand $M=$ $0.81, S E=0.03)$, all $p>.2{ }^{1}$

\section{Discussion}

We aimed to measure the effect of object-based attention on oculomotor programming. Our findings parallel those in the keypress condition. Here, saccade latencies were fastest at the cued location, as compared to all other locations. This finding supports findings in the previous literature (Abrams \& Jonides, 1988; Crawford \& Müller, 1992; Dorris \& Munoz, 1998; Kawagoe et al., 1998; Kustov \& Robinson, 1996; Murray \& Giggey, 2006; Rothkirch et al., 2013; Takikawa et al., 2002) showing that the deployment of space-based attention shortens the saccade latency at the attended location. With respect to object-based attention, saccade latencies were faster for targets at the same-object location than for those at the different-object location. We observed no effect of object orientation for either the saccade or the keypress experiments, although the object-based effect was numerically smaller in the horizontal than in the vertical orientation with keypress responses (Exp. 1a). A speed-endpoint accuracy trade-off was not evident. Indeed, saccades to the different-object locations slightly undershot the target, more so than saccades to the same-object location. Taken together, these results suggest that object-based attentional selection is responsible for the observed saccade latency differences between the sameobject and different-object locations.

Because the peripheral cue in this experiment was also predictive of the target location (i.e., a hybrid cue), the object-based effect could have been driven by either the endogenous or exogenous properties of the cue. In the next two experiments, we further investigated whether purely exogenous or endogenous cues can drive object-based effects, as measured by saccade latency.

\footnotetext{
${ }^{1}$ We also examined the curvature of the initial saccade trajectories as a function of the target location (Van der Stigchel \& Theeuwes, 2005). The initial trajectory deviations did not differ between the same-object and different-object locations ( $M=3^{\circ}$ away from the cued location).
} 


\section{Experiment 2: Exogenous cue}

In this experiment, we used a purely exogenous cue to direct attention. The target could appear at any one of the four ends of the two rectangles with equal probabilities. Macquistan (1997) claimed that an exogenous cue is not only sufficient to direct object-based attention to the cued object, it is the only type of cue that can elicit object-based attention. The role of exogenous cues in evoking object-based attention is very well documented (Abrams \& Law, 2000; Goldsmith \& Yeari, 2003, 2012), which leads us to predict significant effects of both space-based and object-based attention during keypress responses (Exp. 2a). In the eye movement experiment, we expected to find significant effects of space-based attention (Exp. 2b). Finding a correlate of object-based attention during eye movements would indicate that exogenously driven object-based attention is sufficient to influence saccade latencies.

\section{Experiment 2a}

\section{Method}

Participants Fifteen participants (age $\sim 18-30$ years) provided written informed consent and took part in the experiment: All were students from Michigan State University. One participant had taken part in Experiment 1b. The participant recruitment criteria were the same as for Experiment 1a.

Apparatus The apparatus was identical to that of Experiment 1a for the seven participants who participated in the same room in which Experiment 1a had been conducted. For the remaining eight participants (who completed the experiment in a different room), the stimuli were displayed on a 19-in. CRT monitor (resolution $=1,024 \times 768$ pixels) with a vertical refresh rate of $100 \mathrm{~Hz}$, and the viewing distance was $85 \mathrm{~cm}$, ensured by the use of a chinrest.

Stimuli and procedure The sizes and colors of the background, fixation cross, inner areas and outer edges of the rectangles, and the cue and target were the same as in Experiment 1a. Seven participants performed the experiment in the room from Experiment 1a, and eight participants perfomed in another room on a different CRT monitor, in which the luminance values of the stimuli were slightly different (background and inner areas of the rectangles $=0.01 \mathrm{~cd} / \mathrm{m}^{2}$, edges of the rectangles and the fixation cross $=5 \mathrm{~cd} / \mathrm{m}^{2}$, target $=$ $\left.13.5 \mathrm{~cd} / \mathrm{m}^{2}\right)$.

The sequence and duration of the stimuli, and the response modalities were the same as in Experiment 1a. The primary difference between the experiments was the cue validity during target-present trials ( $80 \%$ target-present, $20 \%$ catch). The target could appear at the cued, same-object, different-object, and the opposite (the farthest corner to the cue) locations with equal probabilities. The instructions were the same as in Experiment 1a. There were ten blocks, each consisting of 80 trials. Eye movements were not recorded.

\section{Results}

Eligible trials We excluded all trials in which the RT was shorter than $200 \mathrm{~ms}$ or longer than 1,500 ms. The number of eligible trials in each condition was subjected to a 2 (Orientation: vertical, horizontal) $\times 4$ (Target Location: cued location, same-object location, different-object location, opposite location) repeated measures ANOVA. The proportion of eligible trials in each condition was submitted to a 2 (Orientation: vertical, horizontal) $\times 4$ (Target Location: cued, same-object, different-object) repeated measures ANOVA. None of the effects reached significance (all $p \mathrm{~s}>.1$ ). On average, .94 of trials were eligible for analysis.

Reaction time ${ }^{2}$ A 2 (Orientation: vertical, horizontal) $\times 4$ (Target Location: cued, same-object, different-object, opposite) repeated measures ANOVA was run on the mean keypress RTs (Fig. 4). The main effect of orientation was significant, $F(1,14)=7.97, M S E=63.13, p=.014, \eta_{\mathrm{p}}{ }^{2}=$ 0.36 . The mean RT was faster in the vertical orientation trials $(M=378.47, S E=21.68)$ than in the horizontal orientation trials $(M=382.57, S E=22.06)$. The main effect of object location was also significant, $F(3,42)=6.81, M S E=833.7$, $p=.008, \eta_{\mathrm{p}}{ }^{2}=0.33$; the keypress RT was slower for the cued location $(M=394.83, S E=22.38)$ than for the same-object $(M$ $=374.66, S E=22.42$, Cohen's $d=0.9)$, different-object $(M=$ $379.47, S E=21.4$, Cohen's $d=0.56)$, and opposite $(M=$ 373.12, $S E=22.2$, Cohen's $d=0.74$ ) locations, all $p$ s $<.05$. The RTs for the remaining target location comparisons were not significantly different, all $p s>.05$. The interaction between target location and orientation was also not significant, $F(3,42)=1.71, M S E=267.37, p=.199, \eta_{\mathrm{p}}^{2}=.11$.

\section{Experiment 2b}

\section{Method}

Participants Fifteen participants (age $~ 18-30$ years) provided written informed consent and took part in the experiment: All were students from Michigan State University. Four of the participants (including author G.S.) had also participated in Experiment 1b, and one had also participated in Experiment

\footnotetext{
${ }^{2}$ A 2 (Orientation: vertical, horizontal) $\times 4$ (Target Location: cued location, same object, different object, opposite location) $\times 2$ (Room: old, new) mixed-design ANOVA on the mean keypress RTs showed no indication of a main effect of room or interactions of room with any of the other variables. Thus, we collapsed across the Room factor for the analysis.
} 


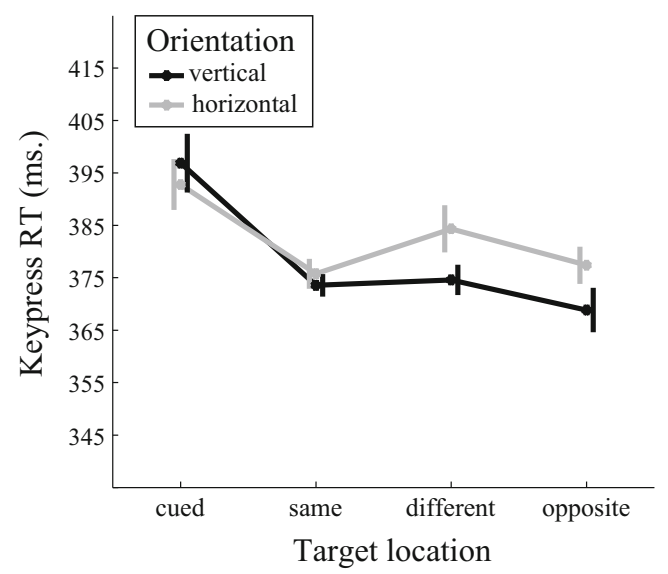

Fig. 4 Mean reaction times (RTs, in milliseconds) as a function of object orientation (vertical vs. horizontal) and target location (cued, same object, different object, opposite). Error bars show within-subjects standard errors, as suggested by Cousineau (2005)

1a. The participant recruitment criteria were the same as in Experiment 1a.

Apparatus and visual stimuli Both the display and stimuli were identical to those of Experiment 1a. Eye movements were recorded by an EyeLink 1000 eyetracker (SR Research, Ontario, Canada) at a sampling rate of $1 \mathrm{kHz}$.

Design and procedure The training procedure was the same as in Experiment 1b, except that we introduced an online drift correction procedure (drift correction had been performed offline in Exp. 1b). The participants were instructed to fixate at the beginning of each trial. If their gaze stayed within $1^{\circ}$ of the fixation cross for at least $500 \mathrm{~ms}$ in a 2-s period, the drift check was skipped and the trial began; otherwise, the experiment paused and a message instructed the participant to fixate and make a keypress that would initiate the drift correction. After drift correction, the participant pressed a key to continue the trial. The trial continued as we explained in Experiment 1b. This online drift correction procedure improved the eyetracking data quality, since slow drifts tend to occur during an experimental session.

The main experiment was identical to Experiment 1b, except for the addition of the drift correction procedure in the training phase (described above). The only other difference between Experiments $1 \mathrm{~b}$ and $2 \mathrm{~b}$ was the validity of the cue during target-present trials. In Experiment 2b, the target could appear at the cued, same-object, different-object, and opposite locations with equal probabilities. The correct eye movement criteria were the same as in Experiment 1b. When a participant failed to make a successful eye movement in a target-present trial for at least three trials in a block, a block was added to compensate for the number of trials with unsuccessful eye movements. There were ten blocks initially, each consisting of 80 trials.

Data preprocessing The preprocessing of the data was the same as in Experiment 1b.

Results

Eligible trials The number of eligible trials in each condition was subjected to a 2 (Orientation: vertical, horizontal) $\times 4$ (Target Location: cued, same-object, different-object, opposite locations) repeated measures ANOVA. None of the effects reached significance (all $p s>.1$ ). On average, .87 of the trials were eligible for the analysis. Only a small proportion of trials were eliminated due to mistakenly making a saccade toward the cued location, and the proportion of such trials did not depend on the orientation, target location, or their interaction $(M=.05$, all $p \mathrm{~s}>.05)$. In terms of corrective saccades, none were needed when the target appeared at the cued location. The proportions of the corrective saccades for the targets at the invalidly cued locations did not depend on orientation (vertical vs. horizontal), object location (same-object, different-object, and opposite), or their interaction, all $p s>.05$ (grand $M=$ $.03, S E=.01)$.

Saccade latency A 2 (Orientation: vertical, horizontal) $\times 4$ (Target Location: cued, same-object, different-object, opposite) repeated measures ANOVA was conducted on the mean saccade latencies (Fig. 5). The main effect of target location was significant, $F(3,42)=51.97, M S E=145.21, p<.001, \eta_{\mathrm{p}}{ }^{2}$ $=.79$. The mean eye movement latency was slower to the cued location $(M=238.17 \mathrm{~ms}, S E=11.01 \mathrm{~ms})$ than to the sameobject $(M=217.21 \mathrm{~ms}, S E=9.63 \mathrm{~ms}$, Cohen's $d=1.84)$, different-object $(M=221.37 \mathrm{~ms}, S E=9.35 \mathrm{~ms}$, Cohen's $d=$ 1.49), and opposite $(M=208.35 \mathrm{~ms}, S E=9.17 \mathrm{~ms}$, Cohen's $d$ $=2.37$ ) locations, all $p \mathrm{~s}<.001$. The saccade latency to the opposite location was faster than those to the cued (Cohen's $d$ $=2.37$ ), same-object (Cohen's $d=1.24$ ), and different-object (Cohen's $d=1.96$ ) locations, all $p \mathrm{~s}<.001$. Importantly, the saccade latency to the same-object location was faster than that to the different-object location ( $p=.011$, Cohen's $d=$ $0.75)$. The effect of orientation $[F(1,14)=3.93, M S E=$ 19.96, $\left.p=.067, \eta_{\mathrm{p}}{ }^{2}=.22\right]$ and the interaction $[F(3,42)=$ $\left.2.36, M S E=27.74, p=.085, \eta_{\mathrm{p}}{ }^{2}=.14\right]$ were not statistically significant.

Saccade gain and landing distance to the target The saccade gain ratios did not differ between the cued, same-object, different-object, and opposite locations, all $p \mathrm{~s}>.095$ (grand $M$ $=1.01)$. The landing distance at the cued location $(M=0.74$, $S E=0.03)$ was smaller than those at the same-object $(M=$ $0.77, S E=0.04)$, different-object $(M=0.77, S E=0.03)$, and opposite $(M=0.78, S E=0.04)$ locations, respective $p \mathrm{~s}=.039$, 


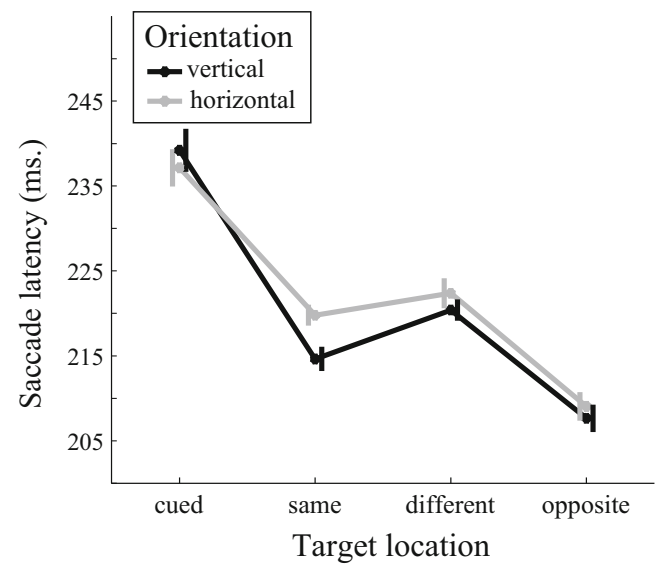

Fig. 5 Mean saccade latencies (in milliseconds) as a function of object orientation (vertical vs. horizontal) and target location (cued, same-object, different-object, opposite). Error bars show within-subjects standard errors, as suggested by Cousineau (2005)

.009 , and .009 . The landing distances did not differ between targets at the same-object, different-object, and opposite locations, all $p \mathrm{~s}>.49 .^{3}$

\section{Discussion}

In this experiment, we examined whether an exogenous cue was capable of eliciting an object-based effect in the doublerectangle paradigm. We found evidence of an object-based effect for saccade latencies, since the same-object saccade latency was faster than the different-object latency, but this did not hold for keypress RTs. Somewhat unexpectedly, we also found that both the saccade latencies and keypress RTs were slowest when the target appeared at the cued location, which is indicative of inhibition of return (IOR). IOR is a decrease in attentional priority at a previously attended location, manifested as a slowing of target detection at that location on subsequent trials (for a review, see Klein, 2000). The cue-target stimulus onset asynchrony (SOA) in Experiment 2 was consistent with IOR effects under spatially exogenous cues (Klein, 2000). Previous studies that have employed the two-rectangle paradigm found both spatial and object-based IOR at much longer SOAs (Jordan \& Tipper, 1999; List \& Robertson, 2007; Reppa \& Leek, 2003). However, in one experiment, List and Robertson (2007, Exp. 2) used a shorter SOA of $340 \mathrm{~ms}$, and still detected spatial IOR in the presence of a significant object-based effect. It is possible that spatial and object-based IOR effects may have different time courses, such that at short SOAs (e.g., $300 \mathrm{~ms}$ ), only spatial IOR is present, but at longer SOAs, both spatial and object-based forms of IOR are present.

\footnotetext{
${ }^{3}$ We also examined the curvature of the initial saccade trajectories as a function of the target location (Van der Stigchel \& Theeuwes, 2005). The initial trajectory deviations did not differ between the same-object and different-object locations $\left(M=2.3^{\circ}\right.$ away from the cued location).
}

Another interesting result of Experiments $2 \mathrm{a}$ and $2 \mathrm{~b}$ is the performance benefit at the location opposite the cued location. We think that such enhanced performance at the location opposite from the cue can be explained by attentional momentum, or the deployment of attentional resources in the opposite direction from the spatially inhibited location, due to IOR. A number of studies have shown not only slower RTs in detection tasks at the cued location due to IOR, but also faster RTs in detecting targets at the farthest location from the cue (Bennett \& Pratt, 2001; Hubbard, 2014; Machado \& Rafal, 2004; Pratt, Adam, \& McAuliffe, 1998; Pratt, Spalek, \& Bradshaw, 1999; Spalek \& Hammad, 2004; Sumner, 2006). Our finding of both inhibition at the cued location and enhancement at the farthest location is consistent with these studies, and suggests that IOR and attentional momentum were operating in tandem.

Our findings suggest that object-based attention can operate even in the presence of spatial IOR. These data provide evidence for a dissociation between space-based and objectbased attention (Duncan, 1984; He et al., 2004; He, Humphreys, Fan, Chen, \& Han, 2008; Vecera \& Farah, 1994), contrary to the idea that object-based attention is merely the spread of space-based attention within a cued object (Hollingworth, Maxcey-Richard, \& Vecera, 2012; Martinez, Ramanathan, Foxe, Javitt, \& Hillyard, 2007; Martínez, TederSalejarvi, \& Hillyard, 2007; Müller \& Kleinschmidt, 2003). Furthermore, these data suggest that saccade latencies are a more sensitive measure of object-based attention than keypress RTs. We concluded that an exogenous cue is sufficient to induce object-based attention, but that this attention is only observed with a more sensitive measure such as saccades.

\section{Experiment 3: Endogenous cue}

Having established that both a hybrid and a purely exogenous cue can elicit object-based effects, we next investigated whether a purely endogenous cue can also drive objectbased effects. Experiments 1 and 2 showed that saccade latencies are more sensitive to effects of attention than are keypress RTs. Thus, saccade latencies are well-suited to the observation of small effects. In addition to our primary goal, we also planned to shed light on the controversy surrounding the role of central cues in object-based attention. On the one hand, Macquistan (1997) observed that only a peripheral cue was capable of eliciting object-based effects of attention. On the other hand, several studies (Abrams and Law, 2000; Chen \& Cave, 2008; Greenberg, 2009; Law \& Abrams, 2002) have shown that central cues could also elicit object-based effects. More recently, some researchers have found that giving particular instructions to participants may be necessary for central cues to elicit object-based attention (Goldsmith \& Yeari, 2003, 
2012). Our aim was to determine whether object-based attention can be elicited by central cues without instructing participants to use any specific strategies. If central cues can elicit object-based attention, saccade latencies may be more capable of detecting the effect than keypress RTs, as we found in Experiment 2.

\section{Experiment 3a}

\section{Method}

Participants Fifteen participants (age $\sim 18-30$ years) provided written informed consent and took part in the experiment; all were students from Michigan State University. Two of the participants had taken part in Experiment 2a, one in both Experiments $2 \mathrm{a}$ and $1 \mathrm{~b}$, and another in both Experiments $2 \mathrm{~b}$ and 1a. The participant recruitment criteria were the same as in Experiment 1a.

Apparatus The apparatus details were identical to those in Experiment 2b.

Stimuli and procedure The sizes and colors of the background, the inner areas and outer edges of the rectangles, and the target were the same as in Experiment 1a, with the following exceptions: The luminance values of the stimuli were slightly altered because we used a different CRT monitor (as we reported in the Stimuli and Procedure section of Exp. 2a). The fixation cross in Experiment 1a was replaced in Experiment $3 \mathrm{a}$ with a fixation square, which was located at the center of the screen (white, $0.02^{\circ} \times 0.02^{\circ}$, luminance $=$ $26 \mathrm{~cd} / \mathrm{m}^{2}$ ). The peripheral cue in Experiment 1a was replaced by a central cue in Experiment $3 \mathrm{a}$, a white line (length $=0.5^{\circ}$, thickness $=0.015^{\circ}$, luminance $=26 \mathrm{~cd} / \mathrm{m}^{2}$ ) extending from the centroid of the fixation square toward one of the four possible target locations (Fig. 6).

The sequence and duration of the stimuli, target probabilities, and response modalities were the same as in Experiment $1 \mathrm{a}$. The primary difference between the experiments was the replacement of the peripheral cue with a central cue in Experiment 3a. There were ten blocks, each consisting of 80 trials. Eye movements were not recorded.
The instructions and data preprocessing were the same as in Experiment 1a.

Results

Eligible trials The proportion of eligible trials in each condition, after preprocessing, was submitted to a 2 (Orientation: vertical, horizontal) $\times 3$ (Target Location: cued, same-object, different-object location) repeated measures ANOVA. None of the effects reached significance (all $p \mathrm{~s}>.1$ ). On average, .97 of the trials were eligible for the analysis.

Reaction time A 2 (Orientation: vertical, horizontal) $\times 3$ (Target Location: cued, same-object, different-object) repeated measures ANOVA was run on the mean keypress RTs (Fig. 7). The main effect of target location was significant, $F(2,28)=58.2, M S E=211.56, p<.001, \eta_{\mathrm{p}}{ }^{2}=.81$ : Keypress RTs were faster for the cued location $(M=347.41$, $S E=12.59)$ than for the same-object $(M=375.51, S E=12.55$, Cohen's $d=1.81)$ and different-object $(M=386.74, S E=$ 13.95, Cohen's $d=2.7$ ) locations, all $p \mathrm{~s}<0.001$. Importantly, RTs were also faster for the same-object than for the different-object location, $p=.006$, Cohen's $d=0.84$. The effect of orientation $[F(1,14)=0.79, M S E=55.86, p=$ $\left..388, \eta_{\mathrm{p}}{ }^{2}=.05\right]$ and the interaction $[F(2,28)=2.46, M S E=$ $\left.205.91, p=.118, \eta_{\mathrm{p}}{ }^{2}=.15\right]$ were not significant

\section{Experiment 3b}

\section{Method}

Participants Fifteen participants (age $\sim 18-30$ years) provided written informed consent and took part in the experiment; all were students from Michigan State University. Except for an author (G.S.) and one other participant (both had participated in Exp. 2a), none had participated in the previous experiments. The participant recruitment criteria were the same as in Experiment 1a.

Apparatus and visual stimuli Both the display and the stimuli were identical to those of Experiment 3a. Eye movements were recorded by an EyeLink 1000 eyetracker (SR Research, Ontario, Canada) with a sampling rate of $1 \mathrm{kHz}$.

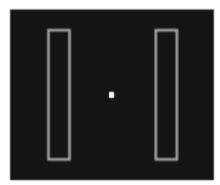

Preview: $1 \mathrm{sec}$

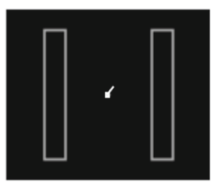

Cue: $100 \mathrm{~ms}$.

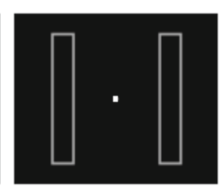

ISI: $200 \mathrm{~ms}$.

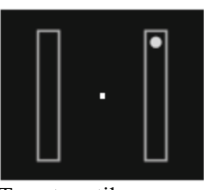

Target: until response $\max .2$ sec.

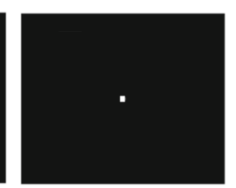

ITI: $500 \mathrm{~ms}$.
Fig. 6 Sequence of a trial in Experiment 3. The rectangles appeared in a horizontal or vertical orientation (vertical is shown). A central cue pointed at one of the corners for $100 \mathrm{~ms}$. After a 200-ms interstimulus interval
(ISI), the target appeared at the cued location (60\%), at the far end of the cued object $(10 \%)$, or at the equidistant corner of the different object $(10 \%)$, or it did not appear $(20 \%)$. ITI = intertrial interval 


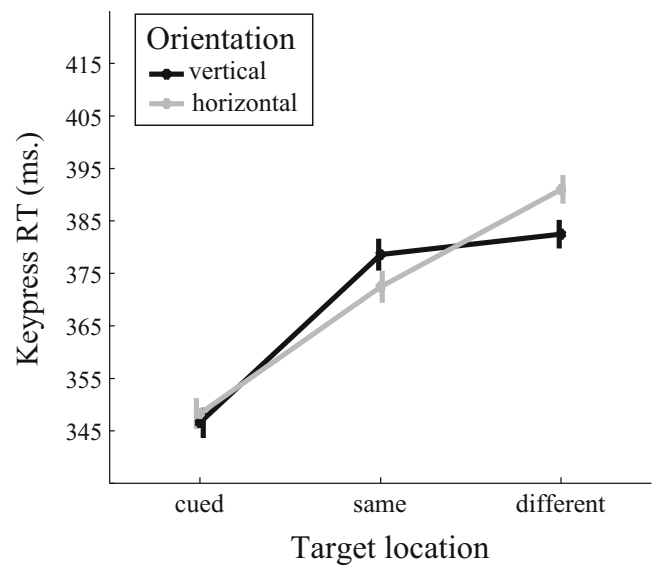

Fig. 7 Mean reaction times (RTs, in milliseconds) as a function of object orientation (vertical vs. horizontal) and target location (cued, same-object, different-object). Error bars show within-subjects standard errors, as suggested by Cousineau (2005)

Procedure The training procedure was the same as in Experiment $2 \mathrm{~b}$. The main experiment procedure was identical to that of Experiment 2b: A drift check and correction phase preceded the main phase of the experiment on each trial. In Experiment 3b, the peripheral cue was replaced with a central cue, which was informative of target location (60\% valid, $10 \%$ same-object, $10 \%$ different-object, $20 \%$ catch). The criteria for correct eye movements, instructions, and data preprocessing were the same as in Experiment $1 \mathrm{~b}$.

\section{Results}

Eligible trials The proportion of eligible trials in each condition, after preprocessing, was submitted to a 2 (Orientation: vertical, horizontal) $\times 3$ (Target Location: cued, same-object, different-object) repeated measures ANOVA. The main effect of target location was significant, $F(2,28)=12.3, M S E<0.01, p<$ $.001, \eta_{\mathrm{p}}{ }^{2}=.47$. The proportion of eligible trials was higher when the target appeared at the cued location $(M=.86, S E=.03)$ rather than at the same-object $(M=.81, S E=.03)$ and different-object $(M=.81, S E=.03)$ locations, $p \mathrm{~s}=.001$. We found no further significant differences between target locations $(p=.903)$. The effect of orientation and the interaction were not statistically significant $(p \mathrm{~s}>.5)$. On average, .83 of the total trials were eligible for the analysis. Only a small proportion of trials were eliminated due to mistakenly executing a saccade toward the cued location, and the proportion of such trials did not depend on orientation, target location, or their interaction $(M=.06$, all $p \mathrm{~s}$ $>.05$ ). In terms of corrective saccades, none were needed when the target appeared at the cued location. The proportions of corrective saccades for the targets at the invalidly cued locations did not depend on orientation (vertical vs. horizontal), object location (same-object, different-object), and their interaction, all $p \mathrm{~s}>.05$ (grand $M=.04, S E=.01$ ).

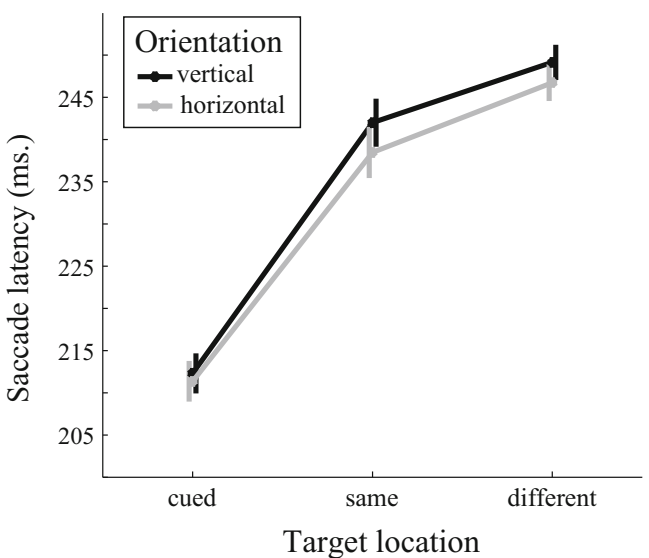

Fig. 8 Mean saccade latencies (in milliseconds) as a function of object orientation (vertical vs. horizontal) and target location (cued, same-object, different-object). Error bars show within-subjects standard errors, as suggested by Cousineau (2005)

Saccade latency A 2 (Orientation: vertical, horizontal) $\times 3$ (Target Location: cued, same-object, different-object) repeated measures ANOVA was conducted on the mean saccade latencies (Fig. 8). The main effect of target location was significant, $F(2$, $28)=66.31, M S E=210.68, p<.001, \eta_{\mathrm{p}}{ }^{2}=.83$. The mean eye movement latency was faster at the cued location $(M=$ $211.84 \mathrm{~ms}, S E=5.93 \mathrm{~ms})$ than at the same-object $(M=$ $240.23 \mathrm{~ms}, S E=7.07 \mathrm{~ms}$, Cohen's $d=2.2$ ) and different$\operatorname{object}(M=247.94 \mathrm{~ms}, S E=7.3 \mathrm{~ms}$, Cohen's $d=2.34)$ locations, all $p \mathrm{~s}<.001$. Importantly, the saccade latency to the same-object location was also faster than that to the different-object location, $p$ $=.006$, Cohen's $d=0.83$. The effect of orientation $[F(1,14)=$ $\left.1.87, M S E=63.16, p=.193, \eta_{\mathrm{p}}{ }^{2}=.19\right]$ and the interaction $[F(2$, 28) $\left.=0.14, M S E=131.35, p=.787, \eta_{\mathrm{p}}^{2}=.01\right]$ were not statistically significant.

Saccade gain and landing distance to the target The saccade gain ratio at the cued location $(M=1, S E=0.01)$ was larger than the ratios at the same-object $(M=0.98, S E=0.01)$ and different$\operatorname{object}(M=0.97, S E=0.01)$ locations, all $p s<.001$. The saccade gain ratios for the same-object and different-object locations were not significantly different, $p=.312$.

The landing position at the cued location was closer to the target centroid $(M=0.77, S E=0.03)$ than were those at the same-object $(M=0.81, S E=0.04)$ and different-object $(M=$ $0.82, S E=0.04$ ) locations ( $p s=.016$ and .044 , respectively). No difference in landing positions was apparent between the same-object and different-object locations, $p=.588 .{ }^{4}$

\footnotetext{
${ }^{4}$ We also examined the curvature of the initial saccade trajectories as a function of the target location (Van der Stigchel \& Theeuwes, 2005). The initial trajectory deviations did not differ between the same-object and different-object locations ( $M=2.7^{\circ}$ away from the cued location).
} 


\section{Discussion}

In Experiment 3, we investigated whether an endogenous cue is capable of affecting saccade latencies and/or inducing object-based attention. Both saccade latencies and keypress RTs were fastest for targets appearing at the cued location (space-based attention). Unlike in previous studies that had claimed that endogenous cues are unable (or unlikely) to produce object-based selection, we found that both saccade latencies and keypress RTs yielded a same-object effect with endogenous cues. Pilz, Roggeveen, Creighton, Bennett, and Sekuler (2012) claimed that object-based attention is sensitive to the orientations of objects, such that object-based effects are more often observed for horizontally oriented objects. One explanation for Macquistan (1997)'s failure to find endogenously driven object-based attention is a possible interaction between object-based attention and orientation. Although Macquistan used both vertically and horizontally oriented rectangles as the objects, he did not examine the effect of orientation in his experiment. If object-based attention is sensitive to orientation, as Pilz et al. concluded, Macquistan might have overlooked a partial endogenously driven objectbased attention effect for a specific orientation. However, our results show that, unlike in Macquistan's findings, objectbased attention can be endogenously driven; and unlike in Pilz et al.'s findings, we found no interaction between target location and orientation. Our results are consistent with recent reports showing that, indeed, orientation may not be the driving factor behind the differences that Pilz et al. observed (AlJanabi \& Greenberg, 2016; Barnas \& Greenberg, 2016; Greenberg et al., 2014).

\section{General discussion}

In this study, we found that space-based attention, driven by either endogenous or hybrid cues, shortens the saccade latency to a target at the cued location. These findings are consistent with studies showing similar effects (Abrams \& Jonides, 1988; Crawford \& Müller, 1992; Dorris \& Munoz, 1998; Kawagoe et al., 1998; Kustov \& Robinson, 1996; Murray \& Giggey, 2006; Rothkirch et al., 2013; Takikawa et al., 2002). More importantly, we examined how object-based attention influences saccade latencies, which has not been systematically investigated. Regardless of the mode of attention (exogenous or endogenous), we showed that the first saccade latency to a target at the same-object location is faster than that to the different-object location. We also show that this saccade latency difference between same-object and different-object targets is not due to a speed-accuracy trade-off between saccade latency and accuracy (Wu, Kwon, \& Kowler, 2010). These results reveal an oculomotor correlate of object-based selection.

\section{First versus second saccade for object-based effects}

Three previous studies have investigated the role of objectbased attention on saccades using Egly et al.'s (1994) doublerectangle cueing paradigm (Malcolm \& Shomstein, 2015; McCarley et al., 2002; Theeuwes et al., 2010). In these experiments, participants made their first eye movement to the cued location, and the main analysis focused on the second saccade (after fixation at the cued location). A potential confound of this approach was that it did not control for the possible guidance of saccades along object contours. Once the eye lands on the target, two elongated and highly salient contours (the edges of the object) are the immediate neighbors of the target. Those lines always extend toward the same-object location, regardless of object orientation, whereas no such elongated contours exist between the target location and the differentobject location. Given that saccades are likely to follow the path of a contour (Wismeijer \& Gegenfurtner, 2012), faster eye movements to the same-object location could be explained by better guidance of saccades due to image contours, instead of a difference in attentional priority. To avoid this potential low-level visual confound, we investigated the first saccade, which, by definition, equated the retinal images for each target location. In other words, wherever the target appeared, the retinal image was identical at saccade initiation. Thus, our measure of the first saccade was not biased by lowlevel image features, and our paradigm allowed us to isolate the effects of object-based attention on saccades.

\section{The role of cue type in object-based attention}

We tested the effectiveness of hybrid (predictive and peripheral), exogenous (nonpredictive and peripheral), and endogenous (predictive and central) cues on object-based attention by measuring both keypress RTs and saccade latencies. All three cue types were capable of producing object-based effects on saccade latencies, though not on all keypress measures. In Experiment 2, in which the cue was peripheral and nonpredictive and the SOA was $300 \mathrm{~ms}$, only saccade latencies showed a significant modulation by object-based attention. Although our primary interest was in determining whether the object-based effect elicited by the hybrid cue in Experiment 1 was driven by its endogenous or exogenous component, our present experiments also shed some light on the controversy regarding the effectiveness of central cues. In an earlier study, Macquistan (1997) claimed that central cues do not evoke object-based selection, whereas others have found that object-based attention can be elicited by central cues (Abrams \& Law, 2000; Al-Janabi \& Greenberg, 2016; Chen \& Cave, 2008; Greenberg, 2009; Law \& Abrams, 2002). Some researchers have claimed that certain task demands (such as widening the focus of spatial attention) are necessary for central cues to elicit object-based attention 
(Goldsmith \& Yeari, 2003, 2012). The participants in the present experiments were not instructed to employ a particular strategy, yet we found that central cues were as capable as peripheral cues of eliciting object-based attention. Our findings, thus, support the view that central cues can elicit objectbased attention.

\section{Difference in the time courses of object- and space-based attention}

In Experiment 2, we observed that both saccade latencies and keypress RTs were much slower at the cued than at the other locations. However, both keypress RTs and saccade latencies were faster at the same-object than at the different-object location, with this same-object advantage only reaching statistical significance for saccade latencies. The observation of object-based facilitation in the presence of space-based inhibition has at least two plausible explanations. First, it is possible that the bracket cue masked the target at the cued location. However, such forward masking should also have been present in Experiments 1a and $1 \mathrm{~b}$, in which we observed a spatial facilitation effect. Moreover, forward masking operates over very short maskto-target intervals (Enns \& Di Lollo, 2000; Ramachandran $\&$ Cobb, 1995). Thus, the 200-ms ISIs in the present experiments should be too long to allow for forward masking. We favor the alternative explanation based on IOR. IOR was originally observed for keypress responses with noninformative cues at relatively long cue-target SOAs (for a review, see Klein, 2000), as well as for saccade latency measures (Abrams \& Dobkin, 1994; Briand, Larrison, \& Sereno, 2000; Dorris, Klein, Everling, \& Munoz, 2002; Rafal, Egly, \& Rhodes, 1994). Some studies have since demonstrated that IOR operates not only at the cued spatial location, but also within cued objects (Gibson \& Egeth, 1994; Jordan \& Tipper, 1998, 1999; Leek, Reppa, \& Tipper, 2003; List \& Robertson, 2007; Reppa \& Leek, 2003; Tipper, Driver, \& Weaver, 1991; Tipper, Weaver, Jerreat, \& Burak, 1994). Our results in Experiment 2 are consistent with extant work that have investigated the time course of object-based IOR using the two-rectangle paradigm with nonpredictive cues. When the cue-target SOA was relatively long (400 to $1,220 \mathrm{~ms}$ ), both spatial and object-based IOR were observed (Exp. 1 in Jordan \& Tipper, 1999; List \& Robertson, 2007; Reppa \& Leek, 2003). However, when the SOA was short $(340 \mathrm{~ms})$, space-based IOR was observed in the presence of an object-based facilitation (Exp. 2 in List \& Robertson, 2007). Our results in Experiment 2 are thus consistent with the previous studies and suggest that, at short SOAs, spacebased inhibition had taken place without any object-based inhibition.
Our results in Experiment 2 provide more evidence for the possible independence, or dissociation, between spaceand object-based attention. We found that object-based facilitation does not necessarily require the presence of space-based facilitation. This dissociation-that is, object-based effects in the presence of spatial inhibition-can also inform the controversy regarding the role of space-based attention in object-based attention. Two classes of theories have attempted to explain how objectand space-based attention are interrelated: (1) that objectbased attention is a spreading of space-based attention within the cued object (Hollingworth et al., 2012; Martinez, Ramanathan, et al., 2007; Martínez, TederSalejarvi, \& Hillyard, 2007; Müller \& Kleinschmidt, 2003) and (2) that object-based attention is fully independent of space-based attention (Duncan, 1984; He et al., 2004; He et al., 2008; Vecera \& Farah, 1994). Our results support the latter view, as do the results of List and Robertson (2007). If space-based attention was a prerequisite of object-based attention, we should not have found an object-based effect in Experiment 2. However, we observed both space-based IOR and object-based effects concurrently. Therefore, we conclude that space-based and object-based forms of attention do not share the same time course for IOR, and that the presence of space-based facilitation is not a requirement for object-based attention.

\section{Saccade planning and the object-based prioritization map}

Our results show that saccade planning (as measured by latency) is facilitated not only at the cued location, but also at the far end of the attended object. Shorter saccade latencies to a target that appears at the cued location have also been consistently observed in several previous studies (Abrams \& Jonides, 1988; Crawford \& Müller, 1992; Dorris \& Munoz, 1998; Kawagoe et al., 1998; Kustov \& Robinson, 1996; Murray \& Giggey, 2006; Rothkirch et al., 2013; Takikawa et al., 2002). This space-based cueing effect can be accommodated within the theoretical framework of a priority map, in which saccades are drawn to the highest-priority location on the map (for reviews, see Bisley \& Goldberg, 2010; Zelinsky \& Bisley, 2015). Our findings support a role of the priority map in saccade planning, because gaze was faster to the highest-priority location than to all other locations. However, the concept of a priority map cannot easily explain how attention is also modulated by the layout of objects and why saccades are also drawn to an attended object. This observation suggests an extension of the priority map concept. Indeed, a protoobject-based saliency model has been proposed to explain object-based attention (Russell, Mihalaş, von der Heydt, Niebur, \& Etienne-Cummings, 2014; Vecera, 2000). In this model, figure-ground segmentation is achieved by 
Table 1 Cohen's $d$ measures for space-based effects (measured by comparing the cued and same-object locations) and object-based effects (measured by comparing the same- and different-object locations) in each experiment

\begin{tabular}{|c|c|c|c|c|c|c|}
\hline & \multicolumn{2}{|c|}{ Experiment 1} & \multicolumn{2}{|c|}{ Experiment 2} & \multicolumn{2}{|c|}{ Experiment 3} \\
\hline & a. RT & b. Latency & a. RT & b. Latency & a. RT & b. Latency \\
\hline Space-based effect size & 0.69 & 1.29 & $0.90^{*}$ & $1.84^{*}$ & 1.81 & 2.20 \\
\hline Object-based effect size & 0.67 & 0.74 & 0.47 & 0.75 & 0.84 & 0.83 \\
\hline
\end{tabular}

${ }^{*}$ Note that the direction of the space-based effect was reversed in Experiment 2

assigning border ownership, wherein the regularities in a scene are grouped together. Such a grouped array attracts attention, as well as saccades, because it becomes the winner of a competition against single, ungrouped features (Russell et al., 2014). Our empirical data provide support for this theory, which is based on model simulations. Even though the attended location has an advantage in saccade latency, a competition between objects seems to take place in addition to the competition between locations. Thus, our findings favor roles for both prioritized locations and objects in saccade preparation. It is worth noting here that this is also consistent with well-accepted theories positing voluntary control over object-based attention (Drummond \& Shomstein, 2010; Greenberg, 2009; Greenberg \& Gmeindl, 2008; Shomstein, 2012).

\section{Comparison between keypress RT and saccade latency}

It is well-established that saccades and attention are closely related (e.g., premotor theory of attention; Rizzolatti et al., 1987), suggesting strong ecological validity for measuring attention via the saccade latency. When a potential target attracts our attention, we typically saccade to it (Herwig \& Schneider, 2014). In general, we found parallel attention effects for keypress RTs and saccade latencies. Thus, saccade latencies also exhibit standard object-based effects previously demonstrated with keypress RTs. However, our data also show that saccade latency is a more sensitive measure for detecting effects of attention. Notably, in Experiment 2, an object-based effect was reliably observed via saccade latencies, but only a small numeric trend was observed for keypress RTs. The effect sizes of our reported statistical tests are another index of sensitivity. In Table 1, we list the Cohen's $d$ s we calculated for both keypress and saccade measures in all experiments. Keypress RT effect sizes were generally smaller than those for saccade latencies; this held for both spacebased and object-based effects of attention. Presumably, the superior sensitivity of saccade latencies in comparison to keypress RTs stems from the ballistic nature of saccades, so that variability is smaller in saccade latencies than that in keypress RTs. This also accords with experimental results showing that, although the oculomotor and hand movement systems are guided by shared attentional resources, the planning of eye and hand movements to an attended target is dominated by the oculomotor system (Khan, Song, \& McPeek, 2011). Given the ecological validity and superior sensitivity of saccades, future research in object-based attention may benefit from utilizing saccade latency as the dependent measure.

\section{Conclusion}

We found that first saccade latencies were facilitated by exogenously and endogenously driven object-based attention. Our observation of object-based effects of attention in the presence of space-based IOR suggests that object-based selection may be independent of space-based selection. Furthermore, as compared to manual keypress RTs, saccade latencies exhibited higher sensitivity in detecting effects of attention. Overall, the oculomotor correlates of object-based attention that we demonstrated in this study are consistent with the idea that attentional priority maps encode (and are influenced by) not only spatial locations, but also perceptual objects.

Author note This research was supported by grants from the US-Israel Binational Science Foundation (No. 2013400, to A.S.G.) and the National Institutes of Health (No. R01EY022727, to T.L.).

\section{References}

Abrams, R. A., \& Dobkin, R. S. (1994). Inhibition of return: Effects of attentional cuing on eye movement latencies. Journal of Experimental Psychology: Human Perception and Performance, 20, 467-477. doi:10.1037/0096-1523.20.3.467

Abrams, R. A., \& Jonides, J. (1988). Programming saccadic eye movements. Journal of Experimental Psychology: Human Perception and Performance, 14, 428-442. doi:10.1037/0096-1523.14.3.428

Abrams, R. A., \& Law, M. B. (2000). Object-based visual attention with endogenous orienting. Perception \& Psychophysics, 62, 818-833. doi:10.3758/BF03206925

Al-Janabi, S., \& Greenberg, A. S. (2016). Target-object integration, attention distribution, and object orientation interactively modulate object-based selection. Attention, Perception, \& Psychophysics. doi:10.3758/s13414-016-1126-3

Atchley, P., \& Kramer, A. F. (2001). Object and space-based attentional selection in three-dimensional space. Visual Cognition, 8, 1-32. 
Awh, E., Armstrong, K. M., \& Moore, T. (2006). Visual and oculomotor selection: Links, causes and implications for spatial attention. Trends in Cognitive Sciences, 10, 124-130.

Barnas, A. J., \& Greenberg, A. S. (2016). Visual field meridians modulate the reallocation of object-based attention. Attention, Perception, \& Psychophysics, 78. doi:10.3758/s13414-016-1116-5

Bennett, P. J., \& Pratt, J. (2001). The spatial distribution of inhibition of return. Psychological Science, 12, 76-80. doi:10.1111/1467-9280. 00313

Bisley, J. W., \& Goldberg, M. E. (2010). Attention, intention, and priority in the parietal lobe. Annual Review of Neuroscience, 33, 1-21. doi: 10.1146/annurev-neuro-060909-152823

Briand, K. A., Larrison, A. L., \& Sereno, A. B. (2000). Inhibition of return in manual and saccadic response systems. Perception \& Psychophysics, 62, 1512-1524.

Chen, Z. (2012). Object-based attention: A tutorial review. Attention, Perception, \& Psychophysics, 74, 784-802. doi:10.3758/s13414012-0322-Z

Chen, Z., \& Cave, K. R. (2008). Object-based attention with endogenous cuing and positional certainty. Perception \& Psychophysics, 70, 1435-1443. doi:10.3758/PP.70.8.1435

Cousineau, D. (2005). Confidence intervals in within-subject designs: A simpler solution to Loftus and Masson's method. Tutorials in Quantitative Methods for Psychology, 1, 42-45.

Crawford, T. J., \& Müller, H. J. (1992). Spatial and temporal effects of spatial attention on human saccadic eye movements. Vision Research, 32, 293-304. doi:10.1016/0042-6989(92)90140-E

Deubel, H., \& Schneider, W. X. (1996). Saccade target selection and object recognition: Evidence for a common attentional mechanism. Vision Research, 36, 1827-1837. doi:10.1016/0042-6989(95) 00294-4

Dorris, M. C., Klein, R. M., Everling, S., \& Munoz, D. P. (2002). Contribution of the primate superior colliculus to inhibition of return. Journal of Cognitive Neuroscience, 14, 1256-1263. doi:10. 1162/089892902760807249

Dorris, M. C., \& Munoz, D. P. (1998). Saccadic probability influences motor preparation signals and time to saccadic initiation. Journal of Neuroscience, 18, 7015-7026.

Drummond, L., \& Shomstein, S. (2010). Object-based attention: Shifting or uncertainty? Attention, Perception, \& Psychophysics, 72, 17431755. doi:10.3758/APP.72.7.1743

Duncan, J. (1984). Selective attention and the organization of visual information. Journal of Experimental Psychology: General, 113, 501517. doi:10.1037/0096-3445.113.4.501

Egly, R., Driver, J., \& Rafal, R. D. (1994). Shifting visual attention between objects and locations: Evidence from normal and parietal lesion subjects. Journal of Experimental Psychology: General, 123, 161-177. doi:10.1037/0096-3445.123.2.161

Enns, J. T., \& Di Lollo, V. (2000). What's new in visual masking? Trends in Cognitive Sciences, 4, 345-352. doi:10.1016/S1364-6613(00) 01520-5

Gibson, B. S., \& Egeth, H. (1994). Inhibition of return to object-based and environment-based locations. Perception \& Psychophysics, 55, 323-339. doi:10.3758/BF03207603

Godijn, R., \& Pratt, J. (2002). Endogenous saccades are preceded by shifts of visual attention: Evidence from cross-saccadic priming effects. Acta Psychologica, 110, 83-102.

Goldsmith, M., \& Yeari, M. (2003). Modulation of object-based attention by spatial focus under endogenous and exogenous orienting. Journal of Experimental Psychology: Human Perception and Performance, 29, 897-918. doi:10.1037/0096-1523.29.5.897

Goldsmith, M., \& Yeari, M. (2012). Central-cue discriminability modulates object-based attention by influencing spatial attention. Experimental Psychology, 59, 132-137.
Greenberg, A. S. (2009). Uncertainty as a guiding principle in the strategic allocation of attention to objects [PhD dissertation]. Baltimore, MD: Johns Hopkins University.

Greenberg, A. S., \& Gmeindl, L. (2008). Strategic control of attention to objects and locations. Journal of Neuroscience, 28, 564-565. doi: 10.1523/JNEUROSCI.4386-07.2008

Greenberg, A. S., Hayes, D., Roggeveen, A., Creighton, S., Bennett, P., Sekuler, A., \& Pilz, K. (2014). Object-based attention is modulated by shifts across the meridians. Journal of Vision, 14(10), 1062. doi: $10.1167 / 14.10 .1062$

He, X., Fan, S., Zhou, K., \& Chen, L. (2004). Cue validity and objectbased attention. Journal of Cognitive Neuroscience, 16, 1085-1097.

He, X., Humphreys, G., Fan, S., Chen, L., \& Han, S. (2008). Differentiating spatial and object-based effects on attention: An event related brain potential study with peripheral cueing. Brain Research, 1245, 116-125.

Herwig, A., \& Schneider, W. X. (2014). Predicting object features across saccades: Evidence from object recognition and visual search. Journal of Experimental Psychology: General, 143, 1903-1922.

Hoffman, J. E., \& Subramaniam, B. (1995). The role of visual attention in saccadic eye movements. Perception \& Psychophysics, 57, 787795. doi:10.3758/BF03206794

Hollingworth, A., Maxcey-Richard, A. M., \& Vecera, S. P. (2012). The spatial distribution of attention within and across objects. Journal of Experimental Psychology: Human Perception and Performance, 38, 135-151. doi:10.1037/a0024463

Hubbard, T. L. (2014). Forms of momentum across space: Representational, operational, and attentional. Psychonomic Bulletin \& Review, 21, 1371-1403. doi:10.3758/s13423-0140624-3

Hunt, A. R., \& Kingstone, A. (2003). Covert and overt voluntary attention: Linked or independent? Cognitive Brain Research, 18, 102 105.

Jordan, H., \& Tipper, S. P. (1998). Object-based inhibition of return in static displays. Psychonomic Bulletin \& Review, 5, 504-509. doi:10. 3758/BF03208829

Jordan, H., \& Tipper, S. P. (1999). Spread of inhibition across an object's surface. British Journal of Psychology, 90, 495-507.

Juan, C. H., Shorter-Jacobi, S. M., \& Schall, J. D. (2004). Dissociation of spatial attention and saccade preparation. Proceedings of the National Academy of Sciences, 101, 15541-15544.

Kanwisher, N., \& Wojciulik, E. (2000). Visual attention: Insights from brain imaging. Nature Reviews Neuroscience, 1, 91-100.

Kawagoe, R., Takikawa, Y., \& Hikosaka, O. (1998). Expectation of reward modulates cognitive signals in the basal ganglia. Nature Neuroscience, 1, 411-416.

Khan, A. Z., Song, J. H., \& McPeek, R. M. (2011). The eye dominates in guiding attention during simultaneous eye and hand movements. Journal of Vision, 11(1), 9. doi:10.1167/11.1.9

Klein, R. M. (1980). Does oculomotor readiness mediate cognitive control of visual attention? In R. Nickerson (Ed.), Attention and performance (pp. 259-276). Hillsdale, NJ: Erlbaum.

Klein, R. M. (2000). Inhibition of return. Trends in Cognitive Sciences, 4, 138-147. doi:10.1016/S1364-6613(00)01452-2

Kowler, E., Anderson, E., Dosher, B., \& Blaser, E. (1995). The role of attention in the programming of saccades. Vision Research, 35, 1897-1916. doi:10.1016/0042-6989(94)00279-U

Kustov, A. A., \& Robinson, D. L. (1996). Shared neural control of attentional shifts and eye movements. Nature, 384, 74-77.

Lamy, D., \& Egeth, H. (2002). Object-based selection: The role of attentional shifts. Perception \& Psychophysics, 64, 52-66. doi:10.3758/ BF03194557

Law, M. B., \& Abrams, R. A. (2002). Object-based selection within and beyond the focus of spatial attention. Perception \& Psychophysics, 64, 1017-1027. doi:10.3758/BF03194753 
Leek, E. C., Reppa, I., \& Tipper, S. P. (2003). Inhibition of return for objects and locations in static displays. Perception \& Psychophysics, 65, 388-395.

List, A., \& Robertson, L. C. (2007). Inhibition of return and object-based attentional selection. Journal of Experimental Psychology: Human Perception and Performance, 33, 1322-1334. doi:10.1037/00961523.33.6.1322

Machado, L., \& Rafal, R. D. (2004). Inhibition of return generated by voluntary saccades is independent of attentional momentum. Quarterly Journal of Experimental Psychology, 57A, 789-796.

Macquistan, A. D. (1997). Object-based allocation of visual attention in response to exogenous, but not endogenous, spatial precues. Psychonomic Bulletin \& Review, 4, 512-515.

Malcolm, G. L., \& Shomstein, S. (2015). Object-based attention in realworld scenes. Journal of Experimental Psychology: General, 144, $257-263$.

Martinez, A., Ramanathan, D. S., Foxe, J. J., Javitt, D. C., \& Hillyard, S. A. (2007). The role of spatial attention in the selection of real and illusory objects. Journal of Neuroscience, 27, 7963-7973. doi:10. 1523/JNEUROSCI.0031-07.2007

Martínez, A., Teder-Salejarvi, W., \& Hillyard, S. A. (2007). Spatial attention facilitates selection of illusory objects: Evidence from eventrelated brain potentials. Brain Research, 1139, 143-152. doi:10. 1016/j.brainres.2006.12.056

McCarley, J. S., Kramer, A. F., \& Peterson, M. S. (2002). Overt and covert object-based attention. Psychonomic Bulletin \& Review, 9, 751-758. doi:10.3758/BF03196331

Moore, C. M., Yantis, S., \& Vaughan, B. (1998). Object-based visual selection: Evidence from perceptual completion. Psychological Science, 9, 104-110. doi:10.1111/1467-9280.00019

Müller, N. G., \& Kleinschmidt, A. (2003). Dynamic interaction of objectand space-based attention in retinotopic visual areas. Journal of Neuroscience, 23, 9812-9816.

Murray, N. P., \& Giggey, K. (2006). Saccadic latency and attentional control: Evidence for the premotor theory of attention. North American Journal of Psychology, 8, 383-396.

Pilz, K. S., Roggeveen, A. B., Creighton, S. E., Bennett, P. J., \& Sekuler, A. B. (2012). How prevalent is object-based attention? PLoS ONE, 7, e30693. doi:10.1371/journal.pone.0030693

Pratt, J., Adam, J. J., \& McAuliffe, J. (1998). The spatial relationship between cues and targets mediates inhibition of return. Canadian Journal of Experimental Psychology, 52, 213-216. doi:10.1037/h0087294

Pratt, J., Spalek, T. M., \& Bradshaw, F. (1999). The time to detect targets at inhibited and noninhibited locations: Preliminary evidence for attentional momentum. Journal of Experimental Psychology: Human Perception and Performance, 25, 730-746. doi:10.1037/ 0096-1523.25.3.730

Rafal, R., Egly, R., \& Rhodes, D. (1994). Effects of inhibition of return on voluntary and visually guided saccades. Canadian Journal of Experimental Psychology, 48, 284-300.

Ramachandran, V. S., \& Cobb, S. (1995). Visual attention modulates metacontrast masking. Nature, 373, 66-68.

Reppa, I., \& Leek, E. C. (2003). The modulation of inhibition of return by object-internal structure: Implications for theories of object-based attentional selection. Psychonomic Bulletin \& Review, 10, 493 502. doi:10.3758/BF03196512

Rizzolatti, G., Riggio, L., Dascola, I., \& Umiltà, C. (1987). Reorienting attention across the horizontal and vertical meridians: Evidence in favor of a premotor theory of attention. Neuropsychologia, 25, 3140. doi:10.1016/0028-3932(87)90041-8

Rolfs, M., \& Carrasco, M. (2012). Rapid simultaneous enhancement of visual sensitivity and perceived contrast during saccade preparation. Journal of Neuroscience, 32, 13744-13752.

Rothkirch, M., Ostendorf, F., Sax, A. L., \& Sterzer, P. (2013). The influence of motivational salience on saccade latencies. Experimental Brain Research, 224, 35-47.
Russell, A. F., Mihalaş, S., von der Heydt, R., Niebur, E., \& EtienneCummings, R. (2014). A model of proto-object based saliency. Vision Research, 94, 1-15. doi:10.1016/j.visres.2013.10.005

Sato, T. R., \& Schall, J. D. (2003). Effects of stimulus-response compatibility on neural selection in frontal eye field. Neuron, 38, 637-648.

Sheliga, B. M., Riggio, L., \& Rizzolatti, G. (1994). Orienting of attention and eye movements. Experimental Brain Research, 98, 507-522.

Shepherd, M., Findlay, J. M., \& Hockey, R. J. (1986). The relationship between eye movements and spatial attention. Quarterly Journal of Experimental Psychology, 38, 475-491.

Shomstein, S. (2012). Object-based attention: Strategy versus automaticity. WIRE's Cognitive Science, 3, 163-169.

Shomstein, S., \& Behrmann, M. (2008). Object-based attention: Strength of object representation and attentional guidance. Perception \& Psychophysics, 70, 132-144. doi:10.3758/PP.70.1.132

Shomstein, S., \& Yantis, S. (2004). Configural and contextual prioritization in object-based attention. Psychonomic Bulletin \& Review, 11, 247-253. doi:10.3758/BF03196566

Smith, D. T., \& Schenk, T. (2012). The premotor theory of attention: Time to move on? Neuropsychologia, 50, 1104-1114.

Spalek, T. M., \& Hammad, S. (2004). Supporting the attentional momentum view of IOR: Is attention biased to go right? Perception \& Psychophysics, 66, 219-233.

Sumner, P. (2006). Inhibition versus attentional momentum in cortical and collicular mechanisms of IOR. Cognitive Neuropsychology, 23, 1035-1048.

Takikawa, Y., Kawagoe, R., Itoh, H., Nakahara, H., \& Hikosaka, O. (2002). Modulation of saccadic eye movements by predicted reward outcome. Experimental Brain Research, 142, 284-291.

Theeuwes, J., Mathôt, S., \& Kingstone, A. (2010). Object-based eye movements: The eyes prefer to stay within the same object. Attention, Perception, \& Psychophysics, 72, 597-601. doi:10. 3758/APP.72.3.597

Thompson, K. G., Bichot, N. P., \& Schall, J. D. (1997). Dissociation of visual discrimination from saccade programming in macaque frontal eye field. Journal of Neurophysiology, 77, 1046-1050.

Thompson, K. G., Biscoe, K. L., \& Sato, T. R. (2005). Neuronal basis of covert spatial attention in the frontal eye field. Journal of Neuroscience, 25, 9479-9487.

Tipper, S. P., Driver, J., \& Weaver, B. (1991). Object-centred inhibition of return of visual attention. Quarterly Journal of Experimental Psychology, 43A, 289-298. doi:10.1080/14640749108400971

Tipper, S. P., Weaver, B., Jerreat, L. M., \& Burak, A. L. (1994). Objectbased and environment-based inhibition of return of visual attention. Journal of Experimental Psychology: Human Perception and Performance, 20, 478-499. doi:10.1037/0096-1523.20.3.478

Van der Stigchel, S., \& Theeuwes, J. (2005). Relation between saccade trajectories and spatial distractor locations. Cognitive Brain Research, 25, 579-582.

Vecera, S. P. (2000). Toward a biased competition account of objectbased segregation and attention. Brain and Mind, 1, 353-384.

Vecera, S. P., \& Farah, M. J. (1994). Does visual attention select objects or locations? Journal of Experimental Psychology: General, 123, 146160. doi:10.1037/0096-3445.123.2.146

Wismeijer, D. A., \& Gegenfurtner, K. R. (2012). Orientation of noisy texture affects saccade direction during free viewing. Vision Research, 58, 19-26.

Wu, C. C., Kwon, O. S., \& Kowler, E. (2010). Fitts's Law and speed/ accuracy trade-offs during sequences of saccades: Implications for strategies of saccadic planning. Vision Research, 50, 2142-2157.

Zelinsky, G. J., \& Bisley, J. W. (2015). The what, where, and why of priority maps and their interactions with visual working memory. Annals of the New York Academy of Sciences, 1339, 154-164. 